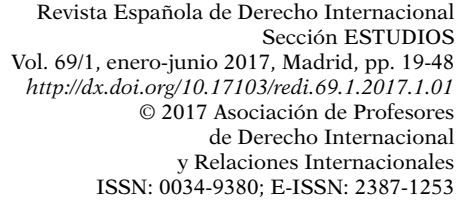

\title{
¿QUÉ NORMA DE CONFLICTO DE LEYES HAY QUE ADOPTAR PARA DETERMINAR LA LEY APLICABLE A LAS CUESTIONES PREVIAS A EFECTOS DE LA SUCESIÓN?*
}

\author{
Santiago Álvarez GoNZÁLEZ
}

SUMARIO: 1. INTRODUCCIÓN.-2. LA CUESTIÓN PREVIA EN DERECHO INTERNACIONAL PRIVADO.-2.1. Una aproximación clásica y formal.-2.1.1. El problema de la pregunta.-2.1.2. El problema de las soluciones.-2.2. Una aproximación funcional sustantiva.-2.3. Una aproximación funcional de proximidad.-2.4. Tratado de indecisión.-3. LA ARTICULACIÓN DE UNA RESPUESTA EN TÉRMINOS DE LEY APLICABLE.-3.1. Los déficits de la pregunta: el progresivo desplazamiento de las cuestiones de ley aplicable por el "método» del reconocimiento.-3.2. Las respuestas dadas a la Pregunta núm. 13 del Libro Verde.-3.3. Los precedentes en el Derecho de la UE.-3.4. Las señales contrapuestas procedentes de la Comisión y del Parlamento en materia sucesoria.-3.5. Las señales contrapuestas procedentes de la doctrina.-4. RECAPITULACIÓN.-4.1. La delimitación del ámbito de aplicación del Reglamento como factor de solución implícita.-4.2. Armonía interna versus armonía internacional en la UE.-5. CONCLUSIÓN.

\section{INTRODUCCIÓN}

1. Aunque el tiempo pasa que es una barbaridad, los familiarizados con el tema de las sucesiones internacionales habrán identificado en el título de las presentes reflexiones la Pregunta núm. 13 de las que se formulaban en el Libro Verde Sucesiones y Testamentos ${ }^{1}$. Decía entonces la Comisión que «la ley aplicable a la sucesión hace a veces depender su liquidación de la respuesta a una cuestión llamada "previa", que puede regularse por otra ley: validez de un matrimonio o de una unión de hecho, determinación de una

\footnotetext{
* El presente trabajo se realizó en el marco del Proyecto de Investigación del Plan Nacional de I+D+i, «Sucesiones internacionales. El Reglamento 650/2012 y su interacción con el Derecho civil nacional»(Ref. DER2013-43391-R), subvencionado por el Ministerio de Economía y Competitividad y el FEDER, y dentro del Programa de consolidación y estructuración de unidades de investigación competitivas del Sistema universitario de Galicia (exp. GPC2014/024). Santiago Álvarez González es Catedrático de Derecho internacional privado en la Universidad de Santiago de Compostela. Email del autor: santiago.alvarez@usc.es.
}

1 Bruselas, 1 de marzo de 2005, $\operatorname{COM(2005)~} 65$ final. 
filiación, etc.». Y a continuación lanzaba la pregunta. Una pregunta que quizá no fue del todo bien comprendida. Las respuestas dadas desde España resultan elocuentes en este sentido: tan heterogéneas como, en algunos casos, pintorescas ${ }^{2}$. El lector iniciado sabrá que hay que pasar de puntillas sobre dichas respuestas; no debe destinarse más tiempo del empleado en leerlas para tratar de articularlas. Es imposible.

2. La Pregunta núm. 13 planteaba una incógnita que once años después sigue sin una respuesta clara. En descargo de esta ausencia y de tan heterogénea comprensión, hay que adelantar que quizá no estuvo bien formulada o que se formuló con cierta dosis de anacronismo. Más propia de cuarenta o cincuenta años antes y ajena a la evolución moderna del Derecho internacional privado (DIPr), al ámbito de integración en el que se formulaba y a la retracción del llamado método del conflicto de leyes para abordar una parte significativa de las cuestiones previas que la Comisión tenía en mente.

3. En cualquier caso, se trata de una pregunta que hace referencia a un problema real o que puede ser real: nociones cruciales en el Derecho de sucesiones, como la de cónyuge, viudo o viuda, hijos o descendientes, ascendientes, parentesco hasta determinado grado, conviviente en pareja estable, registrada o no... están fuera de la regulación del Reglamento 650/2012 ${ }^{3}$, y potencialmente dentro de la sucesión. Su art. 1.2.a) señala expresamente que: «Quedarán excluidos del ámbito de aplicación del presente Reglamento: a) el estado civil de las personas físicas, así como las relaciones familiares y las relaciones que, con arreglo a la ley aplicable a las mismas, tengan efectos comparables» ${ }^{4}$. Exclusión que hace referencia a realidades imprescindibles que condicionan o determinan la sucesión.

4. El Reglamento decide cuál es la ley aplicable a la sucesión mortis causa y esta decidirá si el cónyuge tiene o no derechos hereditarios, si los tienen los hijos o descendientes, si los ascendientes, si el superviviente de la pareja estable o registrada. Su art. 23.2.b) establece que la ley sucesoria regirá en particular «la determinación de los beneficiarios, de sus partes alícuotas respectivas y de las obligaciones que pueda haberles impuesto el causante, así como la determinación de otros derechos sucesorios, incluidos los derechos sucesorios del cónyuge o la pareja supérstites». Lo que no dice el Reglamento es quién es cónyuge, quién hijo, etc. Se trata esta de una de las cuestiones que quedan fuera del Reglamento y que pueden socavar una de las finalidades más recognoscibles de los reglamentos, de todos ellos en general, cual es la

2 Los documentos relativos al Libro Verde y a las respuestas al mismo los consulto en ec.europa.eu/ justice/newsroom/civil/opinion/050301_en.htm, por lo que no haré subsiguientes referencias a este sitio.

3 Reglamento (UE) núm. 650/2012, del Parlamento Europeo y del Consejo, de 4 de julio, relativo a la competencia, la ley aplicable, el reconocimiento y la ejecución de las resoluciones, a la aceptación y la ejecución de los documentos públicos en materia de sucesiones mortis causa y a la creación de un certificado sucesorio europeo (DO L 201, de 27 de julio de 2012). En adelante, el Reglamento.

${ }^{4} \mathrm{El}$ apartado d) del mismo precepto excluye también «las cuestiones relativas a los regímenes económicos matrimoniales, así como a los regímenes patrimoniales resultantes de las relaciones que la ley aplicable a las mismas considere que tienen efectos comparables al matrimonio». 
consecución de una misma solución para una misma situación sea cual sea el Estado miembro (EM) en el que se plantee ${ }^{5}$. Trasladada la idea a las sucesiones internacionales, ello significaría la exigencia de una misma solución para la misma sucesión ${ }^{6}$. Y ello puede chocar tanto con la diversidad del Derecho comparado cuanto con la distinta concepción, el distinto método que se emplee en cada EM para resolver aquellas incógnitas. Además, aunque se haya querido rebajar el problema por las peculiares relaciones y la evolución en cierto modo convergente del Derecho entre los $\mathrm{EM}^{7}$, lo cierto es que el carácter erga omnes del Reglamento (art. 20) hace que la ley aplicable a la sucesión pueda ser tanto la francesa o la alemana, como la senegalesa o la de Corea del Sur. Pero es que, además, incluso sin salir de la UE el concepto de «cónyuge» no es unívoco: baste señalar los EM en los que se admite el matrimonio entre personas del mismo sexo y aquellos en los que aún no. Y otro tanto puede decirse en relación con el vínculo de filiación. Aunque la generalización de las acciones de filiación y las pruebas de ADN rebajan sensiblemente las diferencias en cuanto a las soluciones últimas, siguen existiendo diferencias técnicas (presunciones de paternidad, requisitos o condiciones del reconocimiento voluntario de paternidad...) o radicales, como pueda ser la aceptación o no de la filiación entre los comitentes (padres y o madres de intención) y los nacidos mediante gestación por sustitución ${ }^{8}$.

5. Debo ya señalar que aunque los ejemplos típicos son los referidos, el rango de cuestiones que pueden caer dentro del concepto "cuestión previa» resulta de muy difícil determinación, pues es precisamente la indefinición del concepto una de sus características (y debilidades) más notorias ${ }^{9}$. Se podrían incluir también aspectos que tengan que ver con la propiedad de bienes presuntamente integrantes del patrimonio hereditario o con la existencia y validez de créditos que pueden determinar también el volumen de dicho patrimonio ${ }^{10}$, la validez de una donación a los efectos de su eventual cómputo,

\footnotetext{
5 Se suelen citar recurrentemente el cdo. 6 del Reglamento 593/2008 (Roma I) y el cdo. 6 del Reglamento o 864/2007 (Roma II), si bien hay que matizar que estos hablan, no de la misma solución, sino de «la misma ley nacional».

6 Álvarez González, S., «La ley aplicable a la sucesión por causa de muerte en el Reglamento 650/2012: algunos temas seleccionados», El nuevo marco de las sucesiones en la Unión Europea, Madrid, Consejo General del Notariado, 2014, pp. 43-74, esp. pp. 67-68.

7 SchURIG, K., "Das internationale Erbrecht wird europaisch - Bemerkungen zur kommenden Europaischen Verordnung», Festschrift für Ulrich Spellenberg: Zum 70. Geburtstag, Múnich, Sellier, 2010, pp. 343-353, esp. pp. 350-351.

8 Entre las escasos ejemplos de cuestión previa de filiación en nuestra práctica judicial reciente véase la SAP de Málaga, de 5 de junio de 1993 (AC 1993/1882), aplicación del art. 9.8 CC a la sucesión y del art. 9.4 CC a la filiación (MASEDA RodRíGUEZ, J., "Sucesión internacional: algunos problemas relativos a la aplicación de la norma de conflicto a través de la reciente práctica jurisdiccional española», Dereito, vol. 16, 2007, núm. 1, pp. 295-322, esp. pp. 313-316).

9 MÄsch, G., "Zur Vorfrage im europäischen IPR», en LeIBle, S. y UnBERATH, H. (Hrsg.), Brauchen wir eine Rom 0-Verordnung?, Sipplingen, JWV, 2013, pp. 201-221, esp. pp. 216-217. Las referencias se harán a este trabajo y no al más reciente del mismo autor «Preliminary Question», en LeIBLE, S. (ed.), General Principles of European Private International Law, Países Bajos, Kluwer, 2016, pp. 101-116, que apenas cambia nada. Infra núms. 9 y ss. y 13 y ss.

10 Max Planck Institute for Comparative and International Private Law, «Comments on the European Commission's Proposal for a Regulation of the European Parliament and of the Council on juris-
} 
imputación, reducción o colación ${ }^{11}$, o la determinación del régimen económico matrimonial ${ }^{12}$, entre otros.

6. Dónde, en qué ley, buscar las respuestas a estas y similares dudas era, creo, la pretensión de la Pregunta núm. 13 del Libro Verde, aunque realmente fue más allá e introdujo una acotación accesoria situándose en el cómo: a través de qué norma de conflicto. La Comisión hace en cierta medida hipótesis de la cuestión: saber quién es el cónyuge viudo, o el hijo, o el conviviente..., ¿necesita de una norma de conflicto?

7. La Pregunta núm. 13 abrazó una concepción clásica y hoy creo que en gran medida cuestionada y/o superada de la llamada «cuestión previa». En los siguientes apartados intentaré describir muy sucintamente en qué consiste esta cuestión previa, lo que puede derivarse, si es que existe algún denominador claro, de las respuestas dadas a la pregunta por parte de quienes respondieron al Libro Verde y, por último, los condicionantes de las respuestas que pueden darse, no a la pregunta, sino al problema subyacente. El análisis será esencialmente especulativo, apoyado en la doctrina (en especial la alemana, por ser la que más se ha ocupado del tema) y mezclará desarrollos centrados en las sucesiones con otros inevitablemente genéricos. Con ello, además de seguir indagando en lo que el Reglamento deja al albur de sus extramuros, trataré de conjurar la triskaidekaphobia y de arrojar luz sobre un problema de indudable trascendencia práctica. Adelanto ya, para quien busque respuestas categóricas, que este viaje no lleva a ningún puerto seguro, por lo que su valor, si alguno, habrá de buscarse en el camino. Quien sea adicto a las certezas puede ahorrárselo.

8. Una última acotación: comoquiera que el espacio es limitado y las posibles respuestas a la Pregunta núm. 13 de enjundia suficiente, no abordaré el capital tema de la inadaptación o desajuste que puede aparecer en la aplicación de la ley rectora de la cuestión principal, una vez resuelta la cuestión previa. Ciertamente no solo basta con saber si hay matrimonio o si hay vínculo de filiación, etc., sino de saber si el matrimonio o la filiación que existen son equiparables a los que prevé el estatuto sucesorio. Hoy ya no vale la afirmación de Leo Raape según la cual «hay que tener en cuenta - decía - el hecho de que matrimonio vale [como] matrimonio y que el parentesco matrimonial vale [como] parentesco matrimonial [...] podemos pues evitar el examen sobre si el matrimonio, en el sentido de la ley de conclusión del mismo y en el sentido de la ley [rectora] de la sucesión significa

diction, applicable law, recognition and enforcement of decisions and authentic instruments in matters of succession and the creation of a European Certificate of Succession», núms. 5 y ss.

${ }^{11}$ Corneloup, S., «Les questions préalables de statut personnel dans le fonctionnement des règlements européens de droit international privé», Travaux du comité français de droit international privé, 2011-2012, pp. 189-222, esp. p. 191.

12 KLeINSchmidt, J., «Optionales Erbrecht: Das Europäische Nachlasszeugnis als Herausforderung an das Kollisionsrecht», RabelsZ, 2013, pp. 723-785, esp. p. 764. Entre los escasísimos ejemplos de la práctica judicial, STS núm. 1148/2004, de 2 de diciembre (RJ 2004/7908): aplicación del art. 9.8 CC a la sucesión y de los arts. 9.2 y $9.3 \mathrm{CC}$ al régimen económico matrimonial. 
lo mismo» ${ }^{13}$. Hoy en día lo que significa «matrimonio» $\mathrm{y}$, consiguientemente, cónyuge puede ser muy distinto en los diversos ordenamientos jurídicos. Ambos aspectos, el sí y el qué, suelen ir del brazo, pero aquí me limitaré exclusivamente a desgranar las posibles respuestas a la Pregunta núm. 13 y los problemas que (todas) ellas plantean.

\section{LA CUESTIÓN PREVIA EN DERECHO INTERNACIONAL PRIVADO}

\subsection{Una aproximación clásica y formal}

\subsubsection{El problema de la pregunta}

9. Sin pretensión ni posibilidad de exhaustividad creo necesario decir por qué he considerado la pregunta deficientemente formulada y para ello es preciso señalar (o aventurar) qué tenía en mente la Comisión al plantearla.

10. Como en el anterior epígrafe adelanté, la Comisión pregunta por una «norma de conflicto». Qué norma de conflicto hay que adoptar.. Presupone que saber quién es el hijo, el viudo, el conviviente del causante, lo decide una determinada ley y que esa ley se identifica a través de una norma de conflicto. Está, de esta forma, asumiendo una visión en cierto modo clásica -y en todo caso recognoscible- del llamado problema de la «cuestión previa». Determinada la ley aplicable a la cuestión principal, en el caso que nos ocupa y por simplificar, la ley sucesoria, de la forma que fuere (hoy a través de los arts. 21 y ss. del Reglamento), sería preciso resolver una cuestión previa que, a priori, podría recibir respuestas diferentes (porque si no fuese así no habría problema).

11. No obstante, incluso dentro de estos parámetros clásicos, debe acordarse que no existe ni siquiera un acuerdo sobre la fisonomía de la «cuestión previa»; sobre qué entender por «cuestión previa». La misma terminología se utiliza para hacer referencia a cuestiones distintas que aparecen incluso en momentos distintos en el proceso de identificación de la ley aplicable. Para muestra, varios ejemplos ilustrativos sacados de la doctrina española: mientras que algunos vinculan el problema al supuesto de hecho de la norma de conflicto ${ }^{14}$, otros lo vinculan a su consecuencia jurídica ${ }^{15}$. Nada de extraño en una construcción esencialmente doctrinal, en la que las posturas son múltiples y variadas ${ }^{16}$, donde incluso se ha hablado de "cuestión previa» en

13 RAAPE, L., «Les rapports juridiques entre parents et enfants comme point de départ d'une explication pratique d'anciens et de nouveaux problèmes fondamentaux du droit international privé», Recueil des cours, t. 50 (1934-IV), pp. 399-544, esp. p. 511.

${ }^{14}$ Garcimartín Alférez, F. J., Derecho internacional privado, 3. a ed., Cizur Menor, Civitas, 2016, p. 312 .

15 Fernández Rozas, J. C. y Sánchez Lorenzo, S., Derecho internacional privado, 9. a ed., Cizur Menor, Civitas, 2016, pp. 159-160.

16 Pecourt García, E., "Problemática de la cuestión preliminar en Derecho internacional privado», Revista de Derecho Español y Americano, 1966, pp. 11-60, esp. pp. 16 y 22 y ss., entre otras. Imprescindible. 
relación con la interpretación y aplicación de las normas de nacionalidad del foro ${ }^{17}$. La doctrina alemana es más pulcra y en las dos posturas extraídas de la española diferenciaría una Erstfrage de una Vorfrage ${ }^{18}$, y después de marcar la diferencia, no es descartable que nos ofreciese la misma propuesta para solucionar ambas ${ }^{19}$. También se han distinguido dentro de las categorías en las que nos movemos la Teilfrage, la Nachfrage o la Nebenfrage, como figuras vinculadas entre sí y con la cuestión previa ${ }^{20}$. No resultan relevantes para nuestra Pregunta núm. 13, por lo que evitamos entrar en la discusión tanto sobre su existencia individualizada, cuanto sobre su recíproca delimitación ${ }^{21}$, pero sí es conveniente que nos quedemos con esta complejidad aparejada a la noción, al concepto. Y puestos a diferenciar, hay quien se libera del estricto marco de la ley aplicable y la norma de conflicto y habla también, asumiendo una cierta heterodoxia, de cuestiones previas en materia de competencia judicial internacional y de reconocimiento de decisiones ${ }^{22}$.

12. A mi juicio, la Pregunta núm. 13 del Libro Verde se refería a lo que podría considerarse como "cuestión previa» en sentido estricto o en el más clásico sentido. Un problema que aparece en la fase de aplicación de la ley sustantiva rectora de la cuestión principal y que es susceptible de recibir una respuesta desvinculada de la que recibe la cuestión principal. Tras la delimitación de sus perfiles por G. Melchior y W. Wengler (aunque el problema ya se había descrito antes) ${ }^{23}$, la cuestión previa toma una cierta carta de naturaleza a partir de la que se construyen todas sus variantes. Además, situados en el marco de la pregunta del Libro Verde, dicha respuesta desvinculada y potencialmente autónoma vendrá dada por una norma de conflicto. Será una respuesta sobre la «ley aplicable» a la cuestión previa ${ }^{24}$.

\subsubsection{El problema de las soluciones}

13. Reducida la categoría en los términos expuestos, lo primero que hay que señalar es que las potenciales respuestas, siempre en un plano teórico,

17 SÁnchez Rodríguez, L. I., «La cuestión previa en el Derecho español de la nacionalidad», $A D C$, 1977, pp. 763-807, esp. pp. 763-775, en lo que aquí nos interesa.

18 BernitT, C. Ch., Die Anknüpfung von Vorfragen im europäichen Kollisionsrecht, Tubinga, Mohr Siebeck, 2010, pp. 12 y ss. Eso sí, sin identificar la Erstfrage con la Haupfrage (cuestión principal), como hacen Calvo Caravaca, A. L. y Carrascosa González, J., Derecho internacional privado, vol. I, 16. a ed., Granada, Comares, 2016, p. 481, quizá fruto de un mero lapsus línguae.

19 GössL, S. L., «Die Vorfrage im Internationalen Privatrecht der EU», ZfRV, 2011-2, pp. 65-72, esp. p. 71, de forma plenamente consciente (p. 67).

20 Ya Melchior, G., Die Grundlagen des deutschen internationalen Privatrechts, Berlín y Leipzig, W. de Gruyter, 1932, pp. 258-263.

21 BernitT, C. Ch., op. cit., pp. 9-22.

22 Corneloup, S., op. cit., passim.

23 Melchior, G., op. cit., pp. 245-265, con referencias a autores anteriores (KAHN, RAAPE, ANZILOTTI) a los que, sin embargo, no reconoce un tratamiento global del problema (pp. 248-249); WENGLER, W., «Die Vorfrage im Kollisionsrecht», RabelsZ, 1934, pp. 148-251.

24 Así lo asume también para el Reglamento, Bonomi, A., «Art. 1», en Bonomi, A. y Wautelet, P., Derecho europeo de sucesiones, Cizur Menor, Civitas, 2015, núms. 15-19. 
son múltiples y muy heterogéneas. La historia doctrinal en torno a la cuestión previa solo es uniforme en un aspecto: la inexistencia de uniformidad. $\mathrm{O}$, dicho de otro modo, la existencia de propuestas aparentemente firmes pero surtidas de tantas excepciones, matizaciones y flexibilizaciones que apenas cabe una sistematización fiel ${ }^{25}$.

14. No obstante, en este panorama es preciso reconocer que la gran opción que aparece en todas las aproximaciones doctrinales de forma recurrente es la preferencia por aplicar a la cuestión previa bien la norma de conflicto del foro (lex formalis fori, o solución independiente), bien la norma de conflicto de la lex causae rectora de la cuestión principal (lex formalis causae o solución dependiente). Y creo que debe también resaltarse que la segunda aparece como una excepción a la primera, y no al revés. Dicho con otras palabras, que existe una especie de originaria legitimación de la solución independiente que conduce a quienes defienden la contraria a soportar un mayor peso en la argumentación ${ }^{26}$.

15. En todo caso, lo cierto es que incluso en aquellas propuestas que huyen de dogmatismos y abogan por soluciones ad hoc para diferentes grupos de casos, la presencia de esta dualidad, al menos en el ámbito sucesorio en el que nos movemos, es tremendamente significativa de la fuerza tópica de esta gran opción ${ }^{27}$. Obviamente, esto pasa porque la cuestión principal se rija por una ley extranjera, aspecto estructural para algunos y no relevante para otros $^{28}$; en caso contrario, es decir, estando regida la cuestión principal por la ley del foro, no habría alternativa real entre estas dos posturas. También hay que señalar desde ya que esta dualidad firme se ha visto aliñada a lo largo del tiempo por otras posibilidades: la más recurrente es el sometimiento de la cuestión previa a la ley sustantiva rectora de la principal ${ }^{29}$, pero también se ha barajado la ley material del foro ${ }^{30}$, la ley más estrechamente vinculada ${ }^{31}$ (propuesta en la que me parece ver una cierta desespecialización o desidentificación del problema, que el autor no percibe), o soluciones funcionales dependiendo de la materia ${ }^{32}$.

25 Paradigmático, por pionero, Melchior, G., decidido defensor de la solución dependiente «salvo que concurran especiales razones en contrario» (p. 249).

${ }^{26}$ Schurig, K., "Die Struktur des Kollisionsrechtlichen Vorfragenproblems», Festschrift für Gerhard Kegel zum 75 Geburtstag, Stuttgart, Berlín, Köln, Mainz, 1987, pp. 549-598.

27 HenRICH, D., "Vorfragen im Familien-und Erbrecht: eine unendliche Geschichte», Liber Amicorum Klaus Schurig, Múnich, Sellier, 2012, pp. 63-72, esp. pp. 63-64.

28 Pecourt García, E., op. cit., pp. 24-28, con referencias.

29 El llamado «método de la absorción»: SCHMIDT, T. S., «The Incidental Question in Private International Law», Recueil des Courses, t. 233, 1992-II, pp. 303-415, esp. pp. 387-388.

30 Pecourt García, E., op. cit., p. 16, en un plano hipotético que termina rechazando. Nehne, T., Methodik und allgemeine Lehren des europäischen Internationalen Privatrechts, Tubinga, Mohr Siebeck, 2012, pp. 203-204, contempla las cuatro vías señaladas para rechazar las dos últimas por ser incompatibles con la idea misma de cuestión previa.

31 Pecourt García, E., op. cit., pp. 39 y ss., como propuesta firme de solución.

32 Originalmente el método de la absorción vinculado a la ley aplicable a los alimentos es materialmente funcional y quizá, por ello, poco «exportable»: Solomon, D., «Die Anknüpfung von Vorfragen im Europäischen Internationalen Privatrecht», Festschrift für Ulrich Spellenberg..., op. cit., pp. 355-370, esp. p. 362. 
16. En este momento me limitaré a describir las dos opciones clásicas más la que ha adquirido una cierta consolidación (aplicación de la ley sustantiva rectora de la cuestión principal). Un ejemplo gráfico ayudará a simplificar los posteriores desarrollos: siendo aplicable por un juez español la ley francesa a una determinada sucesión, y surgiendo la duda sobre una filiación controvertida respecto del causante (alguien reclama ser su hijo), la decisión sobre la concurrencia o no de este vínculo de filiación podría resolverse: a) de conformidad con la ley a la que remite el art. $9.4 \mathrm{CC}^{33}$ como si se hubiese planteado ante el juez español a título principal (solución independiente o autónoma); $b$ ) de conformidad con la ley a la que remiten los arts. 311.14 y ss. del CC francés ${ }^{34}$ (solución dependiente: recordemos, la ley sucesoria es la francesa), y $c$ ) de acuerdo con la ley sustantiva francesa sobre filiación ${ }^{35}$.

17. Estas alternativas se mueven dentro de una lógica en cierta manera formal. Cada una de ellas trata de privilegiar un determinado tipo de coherencia o armonía. La solución independiente se orienta a tutelar la armonía interna. La filiación de un francés o de un residente en Francia o de cualquier persona, sea cual sea su nacionalidad y su residencia habitual, será tratada por un juez español siempre de la misma manera, surja a título principal, surja en relación con su calidad de presunto heredero, surja como acreedor de una indemnización por daño moral por la muerte accidental del padre, surja en el curso de una reclamación alimenticia [...] en otras palabras, siempre será hijo (o no lo será) con independencia de las distintas leyes que rijan en cada caso la cuestión principal (ley sucesoria, ley rectora de la responsabilidad no contractual, ley rectora de la obligación alimenticia...). Para el ordenamiento español tal sujeto nunca sería hijo y no hijo al mismo tiempo.

18. La solución dependiente, sin embargo, se orientaría a la tutela de la coherencia en la ley rectora de la cuestión principal (en el ejemplo, la ley francesa) y como consecuencia de ello a la consecución de una cierta "armonía internacional» o coherencia internacional de soluciones ${ }^{36}$. Ambas caras de la misma moneda son muy discutibles o, por ser más concreto, aleatorias.

19. Limitándonos a la coherencia dentro de la ley rectora de la cuestión principal, podemos presumir en nuestro ejemplo que aplicar las normas de conflicto francesas sobre determinación de la filiación arrojará una respuesta coherente con la aplicación de sus normas sustantivas sobre derechos sucesorios de los hijos: es lo que presuntamente haría una autoridad francesa llamada a resolver dicha cuestión. Pero ello no es más que una petición de

33 «La determinación y el carácter de la filiación por naturaleza se regirán por la ley de la residencia habitual del hijo en el momento del establecimiento de la filiación». Siguen soluciones subsidiarias que no nos interesan a efectos ejemplificativos.

${ }^{34}$ "La filiation est régie par la loi personnelle de la mère au jour de la naissance de l'enfant; si la mère n'est pas connue, par la loi personnelle de l'enfant». Le siguen otras especiales sobre posesión de estado o reconocimiento voluntario de la filiación, que no nos interesan a efectos ejemplificativos.

35 Arts. 310 y ss. del CC francés, para la filiación natural, y 343 y ss. para la adoptiva.

36 BERnitT, C. Ch., op. cit., pp. 36 y ss. 
principio $^{37}$. Por ejemplo, podría aplicar, sin más, su propio Derecho sustantivo; y aun aplicando sus normas de conflicto sobre filiación, podría descartar una ley extranjera por contrariar su orden público, cuando esa misma ley hipotéticamente no se opondría al orden público español estando en conocimiento la autoridad española ${ }^{38}$. En definitiva, la aplicación de las normas de conflicto de la ley rectora de la cuestión principal no garantiza nada.

20. Incluso superados estos obstáculos, podría concederse que la generalización de la solución dependiente, es decir, que fuese asumida por todos o la mayoría de los sistemas, fortalecería una armonía internacional de soluciones, más allá de la armonía de dos (lex fori -ley rectora de la cuestión principal-) sobre la que pivota la opción o solución dependiente: al menos allí donde fuese aplicable la ley francesa a la cuestión principal, la solución sobre la filiación de quien pretende ser hijo del causante sería la misma. En todo caso, el objetivo tópico de la armonía internacional que parece justificar esta solución estaría demasiado supeditado a factores ajenos al control de la lex fori. En nuestro ejemplo, la pretendida armonía no solo depende de que nuestra concepción sobre la cuestión previa fuese generalmente aceptada, sino de otro factor de más entidad: que la ley aplicable a la cuestión principal también fuese la misma (y generalizada). En fin, vicisitudes estas y otras que convierten en pura teoría de azar la idea de que la solución dependiente consagra la armonía internacional de soluciones.

21. La tercera vía (en el ejemplo, aplicar las normas sustantivas francesas sobre filiación previamente a sus normas sobre sucesiones) también tiende a favorecer una coherencia interna de la ley rectora de la cuestión principal ${ }^{39}$. Es, podríamos decir, una variante de la solución dependiente, desde el punto de vista de los objetivos en torno a la armonía internacional. Es verdad que se trata de una coherencia forzada, puesto que esta solución implica una especie de «nacionalización» de la situación, algo que por hipótesis (estamos ante una situación privada internacional, ante una sucesión internacional) no existe: en el ejemplo, sería tratar la sucesión como si se tratase de una sucesión interna francesa, y no lo es. Pero se trata de una solución que tiene la ventaja de evitar a priori problemas de inadaptación o desajuste a los que potencialmente conducen tanto la solución independiente como la dependiente: cualquiera de estas dos puede determinar la aplicación de dos leyes sustantivas distintas, una a la cuestión principal (sucesión) y otra a la cuestión previa (filiación). Y, por seguir con el ejemplo, no es inverosímil que el concepto de hijo que maneja la ley sucesoria no coincida con el de hijo que resulta de la ley aplicable a la cuestión previa ${ }^{40}$.

37 Van Hoogstraten, M. H., «Le droit international privé néerlandais et la question préalable», De conflictu legum / Essays Presented to R.D. Kollewijn and J. Offerhaus, Leiden, A. W. Sijthoff, 1962, pp. 209-225, esp. p. 215.

38 Posibilidad relevante que ya contemplaba Melchior, G., op. cit., pp. 263-264.

39 LAgARDE, P., «La règle de conflict applicable aus questions préalables», Rev.crit.dr.int.pr., 1960, pp. 459-482, esp. pp. 470-473.

40 Álvarez González, S., Filiación hispano-suiza. Sistemas de Derecho internacional privado y relaciones concernientes a la emigración española, León, Secretariado de Publicaciones, 1989, pp. 261-263, en torno al concepto de filiación alimenticia. 
22. Digamos, por resumir, que la solución independiente por sí misma tiende a alcanzar y efectivamente alcanza la coherencia interna, puesto que el punto de origen y de destino es el mismo: el ordenamiento del foro. Sin embargo, la consecución o la búsqueda de la coherencia de la ley extranjera rectora de la cuestión principal o la armonía internacional a través de la solución dependiente plantea diversas incógnitas: en cuanto a la coherencia dentro de la ley sucesoria, podemos presumirla con las cautelas señaladas; si hablamos de coherencia o armonía internacional en un sentido más amplio, tan solo se aproximaría al objetivo que se le supone cuando concurren dos factores: el primero es que fuese asumida por la ley rectora de la cuestión principal (armonía de dos) y por el mayor número de sistemas posible; el segundo, y fundamental, que la ley rectora de la cuestión principal (y en su caso el resto de sistemas) tuviera las mismas soluciones que el foro en cuanto a la ley aplicable a la cuestión principal ${ }^{41}$. De nuevo un ejemplo ayudará a entender esta idea: aunque en España y en Francia se optase por la solución dependiente (algo que en realidad no ocurre, pues en ambos países es la contraria la preponderante), la armonía internacional en el tratamiento de una sucesión en cuyo seno surge una cuestión previa de filiación pasaría porque ambos sistemas condujesen a la misma ley sucesoria (algo que tampoco ocurría con anterioridad al Reglamento). En caso contrario, la armonía de marras quedaría descartada cualquiera que fuese la solución para la cuestión previa. Este dato - la uniformidad en cuanto a la ley aplicable a la cuestión principal—, como veremos, puede no ser baladí en el ámbito europeo.

\subsection{Una aproximación funcional sustantiva}

23. Una de las características de las soluciones anteriores es lo que se ha calificado como excesivo rigor lógico-formal, lo que ha motivado, entre otras consecuencias, que las excepciones a las propuestas se erijan en alternativas tan intensas como la propia solución ${ }^{42}$. Junto a este modo ortodoxo de enfocar las soluciones a la "cuestión previa», hay otra forma que tiene más en consideración aspectos valorativos o ponderación de intereses directamente vinculados al caso concreto. No se trataría tanto de optar en virtud de preferir la coherencia interna del foro o una coherencia internacional más o menos amplia, sino de valorar los intereses en juego y optar por una solución concreta - y abierta - a la cuestión previa en función de cuál sea la opción que en mayor medida tutela los intereses que se consideran preponderantes. De este modo, la solución a la cuestión previa podría venir dada, alternativamente, por cualquiera de las tres opciones que más atrás he descrito (o por cualquier otra), lo que supone, de facto, un tratamiento formalmente independiente de la cuestión previa respecto de la cuestión principal, pero sustancialmente condicionado por los intereses y valores que presiden la cuestión

\footnotetext{
41 Ya van Hoogstraten, M. H., op. cit., p. 217.

42 Ya Pecourt García, E., op. cit., 32-33. Y la situación no ha cambiado.
} 
principal. Para entender esta aproximación funcional me permitiré traer a colación el supuesto típico a partir del que se ha construido: el de la obligación alimenticia.

24. En efecto, esta forma de abordar el problema tiene un origen histórico plenamente identificable: la polémica surgida en relación a la cuestión previa de estado civil (de filiación, en concreto) en las reclamaciones de alimentos a mediados del siglo pasado, en el marco de la aplicación del Convenio de La Haya de $1956^{43}$. Planteadas las normas de conflicto sobre obligaciones alimenticias (cuestión principal) como normas tendentes a la identificación de una ley favorable a la atribución de alimentos al acreedor, se defendió que la cuestión previa de filiación debía ser resuelta en el mismo sentido en aplicación de la ley (sustantiva) rectora de la cuestión alimenticia: el «favor» previsto para los alimentos podría extenderse también para la filiación, haciendo abstracción, en cierto modo, de las soluciones, dependiente o independiente, que he descrito con anterioridad ${ }^{44}$.

25. La misma idea podría extenderse a la cuestión previa matrimonial en relación con la cuestión principal de filiación, para concluir la necesidad de sustituir las soluciones apriorísticas por soluciones funcionales, dependientes de los intereses y valores presentes en el caso concreto ${ }^{45}$.

26. Digamos, no obstante, que en materia de sucesiones esta aproximación funcional sustantiva no resulta tan evidente. La razón no es otra que la ausencia nítida de una orientación material en las normas de conflicto identificativas de la ley sucesoria. Aun a riesgo de simplificar el discurso, puede afirmarse que ni la norma que remite a la ley de la última residencia habitual del causante ni, en su caso, a la ley del Estado con el que el causante mantuviese un vínculo manifiestamente más estrecho (art. 21 del Reglamento) se orientan específicamente hacia un determinado tipo de delación de la herencia. Y otro tanto podemos decir de la que sí incorpora un elemento sustantivo, la que consagra la professio iuris (art. 22 del Reglamento), pero que lo abandona a la voluntad del disponente. En otras palabras, el Reglamento no plantea de forma apriorística la búsqueda de leyes sucesorias con un sesgo u otro ${ }^{46}$. En este contexto, esta aproximación funcional y abierta, aunque siempre posible ${ }^{47}$, estaría llamada a tener menos operatividad.

${ }^{43}$ Convenio de 24 de octubre de 1956 sobre ley aplicable a las obligaciones alimenticias respecto a menores.

${ }^{44}$ Lagarde, P., «Observations sur l'articulation des questions de statut personnel et des questions alimentaires dans l'application des conventions de droit internacional privé», Conflits et harmonisation. Kollision und Vereinheitlichung. Conflicts and Harmonization, Mélanges en l'honneur d'Alfred E. von Overbeck, Friburgo, Editions Universitaires Fribourg Suisse, pp. 511-528, esp. pp. 521-523, con más doctrina y práctica judicial comparada.

45 Álvarez GonzÁlez, S., Filiación hispano suiza..., op. cit., pp. 238-247, con cita de L. Raape, J. Foyer e, incluso, volviendo sobre sus postulados, W. Wengler.

46 Álvarez González, S., «Las legítimas en el Reglamento sobre sucesiones y testamentos», AEDIPr, t. XI, 2011, pp. 369-406, esp. pp. 338 y ss., donde aparecen matizaciones.

47 Henrich, D., op. cit., pp. 64-65, con dos ejemplos muy ilustrativos en materia de derechos sucesorios en parejas registradas. 


\subsection{Una aproximación funcional de proximidad}

27. Otra quiebra a las soluciones conceptuales viene dada por el abandono de posturas apriorísticas en beneficio de un método casuístico basado en la idea de proximidad. Suele ser en este sentido recurrente la cita de la propuesta del Prof. Kurt Siehr que, sin abandonar, como tantos otros, la dualidad solución dependiente-solución independiente, optaba por un criterio flexible:

«A preliminary question must be answered either directly by the conflicts rules of the forum State or indirectly under the conflicts rules of the jurisdiction which governs the main question. The choice of method depends on the close connection of the preliminary question with the law governing the answer. The closer the connection of the preliminary question with the forum State or with the foreign country, the more likely it is that the law of the closest connection must give the answer to the preliminary question ${ }^{48}$.

28. Es esta una idea plenamente desarrollada en el magnífico trabajo del Prof. Enrique Pecourt, algunos años antes: en 1966. A partir de una selección de grupos de casos sus propuestas caen bajo la cobertura del que denomina "principio del mayor grado de vinculación»" ${ }^{49}$. Su análisis no se articula en términos dogmáticos. El principio de mayor grado de vinculación ratificaría también las soluciones que se basan en la «armonía material de decisiones» o solución independiente ${ }^{50}$. En definitiva, «la imposibilidad de establecer a priori categorías cerradas de prever todo tipo de cuestión preliminar» obligaría a desistir de cualquier intento de clasificación definitiva y a valorar el principio del mayor grado de vinculación como criterio de solución ${ }^{51}$.

29. Me tomaré la libertad de afirmar lo realmente interesante que resulta leer estas reflexiones con perspectiva histórica y valorarlas con idéntica perspectiva.

\subsection{Tratado de indecisión}

30. Aun siendo somero, el análisis efectuado pone de manifiesto la absoluta heterogeneidad de soluciones que desde un punto de vista teórico o doctrinal se han barajado para dar una respuesta al problema de la cuestión previa.

31. Incluso superando o dejando al margen la indefinición sobre los perfiles propios de la cuestión ${ }^{52}$ y centrándonos en la que podríamos llamar

\footnotetext{
48 SIEHR, K., "General Problems of Private International Law in Modern Codifications. De Lege Lata and De Lege Europea Ferenda», YPIL, VII, 2005, pp. 17-61, esp. p. 52.

49 Pecourt García, E., op. cit., pp. 41 y ss.

50 Ibid., pp. 42-43.

51 Ibid., p. 45.

52 Supra núms. 9-12.
} 
cuestión previa en sentido estricto, e incluso situándonos en las dos propuestas de solución más acreditadas, la solución dependiente o ex lege formalis causae (de la cuestión principal) o independiente o ex lege formalis fori, las excepciones devoran a la regla. Resulta muy gráfica y probablemente certera la afirmación de que "realmente no existe [el] problema de la cuestión previa, sino tantos problemas como supuestos en los que puedan surgir cuestiones previas ${ }^{53}$. A pesar de ello, como veremos más adelante, tanto los resultados del Estudio realizado para la Comisión por el Deutsches Notarinstitut y los Profs. H. Dörner y P. Lagarde ${ }^{54}$ como las respuestas directas al Libro Verde que someramente analizaré denotan una cierta asunción de las grandes opciones (solución independiente versus solución dependiente), con el consiguiente desprecio de los matices.

32. En cualquier caso, antes de entrar en ellas considero necesario aclarar el porqué de calificar la Pregunta núm. 13 del Libro Verde como un cierto anacronismo; aclarar por qué la pregunta puede haberse formulado obviando una evolución en la que la visión estrictamente conflictual («qué norma de conflicto hay que adoptar») parece dejar paso a otras vías para solucionar el mismo problema.

\section{LA ARTICULACIÓN DE UNA RESPUESTA EN TÉRMINOS DE LEY APLICABLE}

\subsection{Los déficits de la pregunta: el progresivo desplazamiento de las cuestiones de ley aplicable por el "método» del reconocimiento}

33. Uno de los inconvenientes de la pregunta del Libro Verde vinculada al problema de la cuestión previa en su comprensión clásica es que hace abstracción de que tal problema parece haber perdido la importancia que otrora tenía, al menos en los estrictos términos conflictuales planteados. Por utilizar los ejemplos de la Comisión, el matrimonio (la cualidad de cónyuge del causante), la existencia de una unión de hecho o una unión registrada (la cualidad de conviviente del causante) o la filiación (la calidad de hijo o de padre o madre del causante), son cuestiones que es posible que no dependan de ninguna "norma de conflicto», al menos en aquellos casos en los que se trate de realidades que tienen algún tipo de consolidación o cristalización en un Estado distinto de aquel en el que la cuestión se suscita ${ }^{55}$.

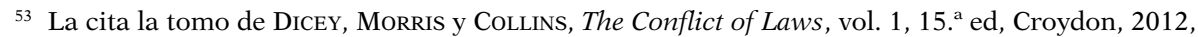
p. 56, 2-051, nota 95, donde se atribuye a GotLIEB, A. E., "The Incidental Question in Anglo-American Conflict of Laws», Canadian Bar Review, 1955, núm. 33, pp. 523 y ss., esp. p. 555.

${ }^{54}$ Étude de droit comparé sur les règles de conflits de juridictions et de conflits de lois relatives aux testaments et successions dans les Etats membres de l'Union Européenne. Étude pour la Commission des Communautés Européennes Direction générale Justice et Affaires intérieures (2002).

55 Una visión general la proporciona la obra de P. LAGARDE (dir.), La reconnaissance des situations en droit international privé, París, Pedone, 2013.
} 
34. La relativa modernidad de esta aproximación ya encontraba su germen en alguna de las propuestas de E. Pecourt: para los casos en los que la situación jurídica controvertida se hubiese originado de acuerdo con un solo Derecho interno, el juez no habría de aplicar norma de conflicto alguna, sino verificar la verdad de la situación jurídica planteada ${ }^{56}$. Mientras que el profesor español se limitaba a uno de sus grupos de casos, en la actualidad el reconocimiento se plantea abiertamente como una alternativa general a la tradicional comprensión de la cuestión previa ${ }^{57}$ y más allá de la cuestión previa, al menos, de forma decidida en el ámbito de la UE.

35. En aquellos casos en los que, a los efectos que ahora nos interesan, nos encontramos ante la valoración de un estatus válidamente adquirido en el extranjero, la pregunta por la ley aplicable a ese estatus tiende a desaparecer en beneficio de la pregunta por las condiciones de reconocimiento de ese estatus. Esta idea, como se ve, desplaza la Pregunta núm. 13 del Libro Verde. Y lo hace además como una impugnación general, como una cuestión de cambio metodológico que puede considerarse como el hit de los últimos años ${ }^{58}$, con obvias manifestaciones en los temas que ahora tratamos que no han estado ausentes en la doctrina española: el matrimonio ${ }^{59}$, las uniones registradas o no ${ }^{60}$, la filiación ${ }^{61}$.

36. Frente a una idea clásica del reconocimiento limitado a decisiones judiciales o no, o actos jurídicos con algún tipo de manifestación formal, documental o registral externa, esta nueva visión ha ampliado el objeto del reconocimiento describiéndolo como «una relación jurídica de Derecho privado, concreta y existente, efectiva en el sentido de que ha sido "objetivada" en un ordenamiento jurídico dado, sea por la intervención de una autoridad pública, que ha hecho su existencia tangible, sea por la eficacia fundada en una apariencia objetiva (creada por el despliegue de efectos durante un tiempo en el seno de un solo ordenamiento jurídico) de un estado o de una relación oponible a terceros» ${ }^{62}$.

37. En este contexto, también hay que adelantar que ese desplazamiento, de existir y de ser absoluto ${ }^{63}$, lo único que hace es cambiar la herramienta para

56 Pecourt García, E., op. cit., p. 39.

57 CoRneloup, S., op. cit., pp. 209 y ss.

58 La doctrina es inabarcable. Además de la ya citada, véase recientemente la recogida por LEHMANN, M., "Recognition as a Substitute for Conflict of Laws?», General Principles of European Private International Law, op. cit., pp. 11-43, nota 1.

59 Orejudo Prieto de los Mozos, P., La celebración y el reconocimiento de la validez del matrimonio en Derecho internacional privado español, Pamplona, Aranzadi, 2002.

${ }^{60}$ QuiÑones EscÁmEZ, A., "Propositions pour la formation, la reconnaissance et d'efficacité internationale des unions conjugales ou couple», Rev.crit.dr.int.pr., vol. 96, 2007, núm. 2, pp. 357-382, esp. pp. 377-378 y 381, desde la perspectiva del «conflicto de autoridades».

61 Álvarez GonzÁLEZ, S., "Reconocimiento de la filiación derivada de gestación por sustitución», $L i$ ber Amicorum Alegría Borrás, Madrid, Marcial Pons, 2013, pp. 77-90, esp. pp. 82-83, con matizaciones.

62 Pamboukis, Ch., "La renaissance-métamorphose de la méthode de reconnaissance», Rev.crit. dr.int.pr., 2008, pp. 513-560, esp. p. 540, la primera cursiva es original, la segunda añadida. LEHMANN, M., op. cit., p. 14, también parte de esta descripción negativa.

${ }^{63}$ Me convence más el «no» de los argumentos de Bucher, A., «La dimension sociale du droit international privé (Cours général)», Recueil des Courses, t. 341, 2009 (2010), pp. 332 y ss., al menos en este momento. 
resolver el problema, no resolverlo en sí mismo. Es cierto que la idea misma de «reconocimiento» tiende a ser más favorable a la admisión de la existencia y efectos de realidades jurídicas, pero partiendo de que seguirá siendo necesario determinar la existencia del estado de cónyuge, o de viudo, o de hijo, o de conviviente, etc., la clave se desplaza hacia las condiciones de reconocimiento a las que la Pregunta 13 del Libro Verde no se refiere, pero que pueden determinar los mismos «conflictos de estatus» que las soluciones a las cuestiones previas en términos de ley aplicable ${ }^{64}$. De nuevo un ejemplo: aun admitiendo que la filiación derivada de gestación por sustitución dentro de una sucesión haya de abordarse en términos de reconocimiento y no de ley aplicable, la enorme heterogeneidad que existe entre los distintos sistemas en torno a concepciones básicas (de derechos y valores superiores involucrados) hará que no sea inverosímil, incluso sin salirnos de la $\mathrm{UE}^{65}$, el rechazo al reconocimiento de dicha filiación con base en razones de contrariedad con el orden público, al menos en algunos EM; a pesar de la progresiva comunitarización de esta noción ${ }^{66}$, de los llamamientos a enfatizar su efecto atenuado como corolario lógico del método del reconocimiento ${ }^{67}$, y de la más general impronta de los derechos humanos ${ }^{68}$, el orden público sigue siendo un obstáculo evidente ${ }^{69}$.

38. También es preciso puntualizar que este debilitamiento del método conflictual en beneficio del método del reconocimiento tiene una caldo de cultivo especialmente favorable en la UE donde el andamiaje jurídico básico o constitucional lo favorece de forma singular. Los ejemplos a los que alude la Pregunta 13 probablemente no puedan abordarse de igual forma en función de que se vinculen o no a la ciudadanía europea y la libre circulación de personas, por ejemplo. Dentro de Europa la impugnación es mucho más fuerte y más efectiva ${ }^{70}$, aunque también se pretende extender la idea sobre otras bases (principalmente derechos humanos) a situaciones provenientes de terceros Estados ${ }^{71}$.

${ }^{64}$ Véase la muy interesante e ilustrativa nota de Romano, G. P., "Conflicts and Coordination of Family Statuses: Towards their Recognition within the EU?», Adoption: Cross-border legal issues, Directorate General for Internal Policies, Policy Department C: Citizens'Rights and Constitutional Affairs. Legal Affairs Petitions, Workshop, 1 de diciembre de 2015, pp. 17-43.

65 Álvarez GonzÁlez, S., "Reconocimiento de la filiación...», op. cit., pp. 87-88. También, A Comparative Study on the Regime of Surrogacy in EU Member States, European Parliament, Directorate General for Internal Policies, Policy Department C: Citizens' Rights and Constitutional Affairs. Legal Affairs, 2013.

66 Álvarez GonzÁlez, S., "¿Orden público europeo versus orden público internacional de cada Estado?», en Bouza, N., GARcía, C. y Rodrígez, A. J. (dirs.), La gobernanza del interés público global, Madrid, Tecnos, 2015, pp. 146-181.

67 Bollée, S., La reconnaissance des situations..., op. cit., pp. 114-115.

${ }_{68}$ Por ejemplo, SSTEDH de 26 de junio de 2014, asuntos 65192/11, Mennesson c. Francia, y 65941/11, Labasse c. Francia.

69 Álvarez González, S., "Reconocimiento de la filiación...», op. cit., pp. 83-86.

70 Por todos, con abundante documentación, GrÜNBERGER, M., «Alles obsolet? -Anerkennungsprinzip vs. Klassisches IPR», en Brauchen wir eine Rom 0-Verordnung?, op. cit., pp. 81-160. Autor que, no obstante, no responde a la pregunta que él mismo se plantea de forma totalmente positiva (pp. 157 y ss.).

71 PANET, A., «La reconnaissance des situations de statut personnel constituées au sein des états tiers», en Bergé, J. S., Frano, S. y Gardeñes Santiago, M. (eds.), Boundaries of European Private International Law, Bruselas, Bruylant, 2015, pp. 679-700. 
39. En este sentido, deben tenerse en cuenta dos factores, en cierta medida contrapuestos, y centrados ya en especial sobre el tema de la sucesión mortis causa. El primero es que el sistema del Reglamento tiende a una cierta correlación entre forum e ius y su razón de ser originaria es abordar los problemas planteados por las sucesiones internacionales en la UE ${ }^{72}$. Ello se traduce en dos reglas generales que conducen, la primera, a la competencia de las autoridades de la última residencia habitual del causante y, la segunda, a la aplicación de esa misma ley de su última residencia habitual. Se está pensando en una sucesión internacional intracomunitaria, que podrá estar presidida y tutelada por ese andamiaje del que hablaba en el párrafo anterior. El segundo factor tiene, a su vez, dos dimensiones: por un lado, ese supuesto tipo o general está plagado de excepciones, incluso sin salirnos del marco europeo y del propio Reglamento ${ }^{73}$; por otro, aunque el Reglamento se aplica en Europa, tiene un alcance universal o erga omnes en el tema de la ley aplicable, que es donde incardinamos el problema de la cuestión previa. La ley sucesoria puede ser la de un Estado miembro o la de cualquier tercer Estado de la comunidad internacional. Y las cuestiones previas que potencialmente se susciten pueden afectar a situaciones vinculadas a la UE: matrimonio celebrado en un Estado miembro, pareja registrada en un Estado miembro, filiación derivada de una técnica de reproducción humana llevada a cabo en un Estado miembro..., amparadas o no por las libertades; y también a situaciones no vinculadas o no vinculadas con la misma intensidad: matrimonio consensual de Iowa (Estados Unidos de Norteamérica), filiación derivada de maternidad subrogada llevada a cabo en Estados Unidos o Ucrania, o la consideración de una unión de hecho entre menores de edad consolidada en la República Popular China y su eventual validación retrospectiva como matrimonio.

40. Sea como fuere y teniendo en muy en cuenta los elementos que he reflejado bajo este epígrafe, la propia formulación de la idea de reconocimiento del estatus relativiza pero no elimina radicalmente la pregunta por la ley aplicable a la cuestión previa. En primer lugar, porque incluso situados en el paradigma del reconocimiento, la unanimidad sobre su funcionalidad omnicomprensiva está lejos de alcanzarse, especialmente en lo que atañe a las «situaciones legales» no documentadas o inscritas en un registro públi$\mathrm{Co}^{74}$. La misma heterogeneidad que veíamos en torno a la delimitación de la cuestión previa y de sus soluciones se aprecia respecto de la capacidad del «método del reconocimiento» para descartar a la ley aplicable. No siempre cabe obviar la pregunta por la ley aplicable ${ }^{75}$.

72 La «razón» económica es absolutamente recurrente desde los primeros momentos y se vincula a sucesiones intracomunitarias. En el Libro Verde (2005) se aludía a 50.000 sucesiones intracomunitarias; la Propuesta ya se veía acompañada de un impacto sobre 450.000 por un valor de 123.000 millones de euros.

73 Por ceñirme a la ley sucesoria, la de la residencia habitual cede ante la más estrechamente vinculada, y ambas ante la ley nacional elegida por el causante (arts. 21 y 22), aunque también existen mecanismos que tratan de restablecer la correlación (arts. 5 y ss.).

74 LehmanN, M., op. cit., pp. 28 y ss.

75 Bucher, A., op. cit., pp. 330-334. 
41. Además, siempre es posible que la cuestión previa surja por primera vez en el momento y ante la autoridad que conoce de la sucesión. Conocemos en un plano meramente interno las disputas que una vez abierta aquella surgen, por ejemplo, sobre la existencia o no de una «separación de hecho», situación que puede ser relevante a efectos de consideración del cónyuge como beneficiario en la herencia o no (arts. 834 o 945 CC, por ejemplo), y que a pesar de lo que pudiera derivar de la semántica (separación de hecho) tiene un componente jurídico en cuanto a su propia existencia que puede variar de un ordenamiento a otro. O podemos pensar directamente en la reclamación de quien nunca ha ostentado estatus de hijo del causante y lo reclama por vez primera en relación con su participación en la herencia, basándose en una presunción de paternidad del causante (marido de la madre, o conviviente, durante algún tiempo...) de la que puede resultar o no un título de legitimación de la filiación en función de que se aplique la ley alegada u otra.

42. Por último, no hay que olvidar que hay cuestiones previas que nada tienen que ver con el modelo del reconocimiento: saber si una donación efectuada en vida por el causante es válida o no, determinar cuál era el régimen económico matrimonial, establecer la existencia de un crédito de la masa hereditaria... serán asuntos típicamente sujetos (en su caso) al escrutinio de la ley aplicable; la que sea.

\subsection{Las respuestas dadas a la Pregunta núm. 13 del Libro Verde}

43. Llegados a este punto, cumple reconocer que el panorama descrito no es excesivamente propicio para dar una respuesta más o menos manejable a la pregunta que nos hacemos. No por haber advertido de ello en la introducción resulta menos inquietante saber que la misma pregunta, no ya sus respuestas, resulta indefinida cuando no impugnada en su propia esencia. Esta impugnación e indefinición condicionó las respuestas de Estados y demás participantes en el proceso de consulta abierto con el Libro Verde. Al igual que las españolas, fueron heterogéneas y a veces indescifrables.

44. En las de los Estados o alguno de sus poderes (normalmente el gobierno, a veces también alguna cámara parlamentaria, ministerio de justicia de Estado federado o parlamento regional) se aprecian distintos intereses, que en ocasiones parecen confundirse. En primer lugar, existe una mayoritaria tendencia a optar por la vía o solución independiente. De manera aislada se admiten excepciones, sin concretar claramente (República Checa, Estonia) y, en ocasiones, esta opción por la solución independiente se ve como un corolario de la idea de que es una cuestión que no debe tratarse por el (entonces planeado) Reglamento: entiendo que subyace no una solución sino una evicción del problema amparada en una perspectiva de «ámbitos de aplicación»: si el matrimonio no es objeto del Reglamento, nada hay que decir al respecto. Mientras que en algún caso, la opción por no regular el problema es nítida (Finlandia) en otros la misma opción se acompaña de la propuesta 
de una solución independiente (Suecia, probablemente también Reino Unido o Países Bajos).

45. A pesar de una cierta confusión sobre el dato, debe desde ya afirmarse que no hay una correlación necesaria entre abogar por la solución independiente y por la ausencia de regulación en el «futuro» instrumento... no es lo mismo. Esta segunda postura, no decir nada al respecto, no conduce directamente a la solución independiente, sino que significaría que cada EM decidiría sobre su posición respecto de la cuestión previa: si aplica sus propias normas de conflicto (solución independiente) o si las de la lex causae (solución dependiente) o cualquier otra solución que pase o no por aplicar una ley.

46. El resto de las contribuciones o respuestas al Libro Verde atestiguan, por un lado, que la comprensión de la pregunta no fue cabal en todos los casos y, por otro, que o bien no se percibió como un tema demasiado importante o bien que, incluso cuando sí se consideró relevante, se optó por afirmaciones más o menos prefabricadas o rutinarias. Resumiendo, puede decirse que aquellas respuestas que se pronuncian con conocimiento de causa de lo que se les pregunta son mayoritariamente partidarias de un tratamiento independiente de la cuestión previa; algunas abogan por que no exista ningún tipo de regulación al respecto; dos optan por que sea la misma ley sucesoria la rectora de tales aspectos ${ }^{76}$, y tres - quizá cuatro- por una solución dependiente ${ }^{77}$.

47. En general, la mayoría que se adhiere a la solución independiente o autónoma se corresponde con los resultados del más atrás citado estudio previo realizado para la Comisión por el Deutsches Notarinstitut y los Profs. H. Dörner y P. Lagarde. El anexo dedicado a las cuestiones previas sobre un total de 15 Estados miembros arrojaba ya en 2002 un balance esclarecedor: en ninguno de ellos prevalecía la solución dependiente, mientras que en todos (salvo Irlanda, carente de resultados) la solución independiente era o bien la regla positiva, o la dominante o al menos la más clara aun siendo controvertida. En todo caso, el estudio concluía que la escasez de decisiones sobre el tema y la división doctrinal sugerían no abordarlo en un futuro Reglamento ${ }^{78}$.

48. Precisamente por estas razones (poca claridad en la práctica, incomprensión, desinterés o formalismo en las respuestas) la posición del Consiglio Nazionale del Notariato exige un lugar singular en este discurso.

${ }^{76}$ Lutz Milzer (Notario, Notariat I Mosbach) y el Prof. Rodríguez Benot, por la Universidad Pablo de Olavide.

77 Bundesnotarkammer (BnotK, Alemania), Consiglio Nazionale del Notariato (Italia) y Shearman and Sterling (sociedad de abogados); quizá también sea esta la propuesta de la Österreichische Notariatskammer, que plantea una distinción entre los supuestos en los que la norma de conflicto está contenida en tratados internacionales y en el resto (aunque el texto francés no termina de ser concluyente). En todo caso, aboga por la solución independiente para las cuestiones previas que se refieran a Derechos reales.

${ }_{78}$ Étude..., op. cit., p. 75. La indefinición del Informe en este punto es utilizada con sarcasmo por Mäsch, G., op. cit., p. 203. 
Primero, porque, como dije es una de las pocas que aboga por una solución dependiente; y, segundo, y más importante, porque lo hace de forma reflexiva y razonada.

49. En primer lugar, denuncia correctamente que un panorama que admita concepciones distintas en los diferentes EM sobre la solución a la cuestión previa puede incentivar el forum shopping. Siempre que quepa la posibilidad de que las autoridades de dos EM distintos puedan tener competencia sobre la misma sucesión, el interesado puede optar en función de cuál de ellas sea más favorable a sus intereses. Las soluciones del Reglamento sí posibilitan la competencia de las autoridades de más de un EM $^{79}$.

50. En segundo término, plantea también la compleja situación en la que incluso al margen de una real controversia entre los beneficiarios de la herencia estos deciden acudir a las autoridades de EM distintos para proceder a la división de la herencia respecto de los bienes que se encuentran en cada uno de los Estados: si en estos dos o más EM se tiene una concepción distinta de la solución a la cuestión previa (o, añado yo, si en ambos se opta por la solución independiente) la aparente falta de controversia no va a evitar un tratamiento disímil de la sucesión.

51. En último lugar, se proyecta esta misma situación conflictiva — señala el Consiglio Nazionale del Notariato-cuando autoridades judiciales y autoridades competentes para expedir el Certificado Sucesorio Europeo (CSE) pertenecen a dos EM distintos.

52. Obviamente, estas situaciones conflictivas valoradas en los términos del Consiglio Nazionale del Notariato no solo precisarían una respuesta singular por parte del Reglamento (o de otra norma europea con igual ámbito), sino que, en el actual momento de desarrollo del Derecho de la UE, conducen casi de forma indefectible a que esta respuesta sea la de la solución dependiente: aplicación de las normas de conflicto competentes de la lex successionis. Volveré sobre las ideas que están detrás de esta propuesta ${ }^{80}$.

\subsection{Los precedentes en el Derecho de la UE}

53. En la normativa positiva de la UE encontramos señales de que la opción por una solución independiente a la cuestión previa es la prevalente. Ello se percibe, por ejemplo en el cdo. 21 del Reglamento 4/2009 sobre alimentos:

«Conviene precisar, en el marco del presente Reglamento, que dichas normas de conflicto de leyes [las del Protocolo de La Haya de 2007] solo determinan la

\footnotetext{
79 Arts. 4 y ss., que establecen diversas posibilidades condicionadas entre los tribunales de la última residencia habitual, nacionalidad, lugar de situación de los «bienes de la herencia» o un forum necessitatis (sobre este sistema, Álvarez TORNÉ, M., La autoridad competente en materia de sucesiones internacionales, Madrid, Marcial Pons, 2013).

${ }^{80}$ Infra núms. 75 y ss.
} 
ley aplicable a las obligaciones de alimentos, y no la ley aplicable al establecimiento de las relaciones familiares en las que se basan las obligaciones de alimentos. El establecimiento de relaciones familiares sigue estando regulado por el Derecho nacional de los Estados miembros, incluidas sus normas de Derecho internacional privado».

El matiz en este caso vendría dado por el Informe Explicativo del Protocolo, que se muestra más ambiguo, planteando abiertamente la posibilidad de continuar con la mayoritaria interpretación de los convenios de 1956 y 1973 (aplicación de la misma ley rectora de la obligación alimenticia) ${ }^{81}$. Curiosamente, además de las impugnaciones generales a esta posibilidad ${ }^{82}$, otras vienen por considerar que con ello se estaría superando el ámbito de aplicación del Reglamento ${ }^{83}$.

54. El Reglamento Roma III también parece abogar por la solución independiente. La exclusión de su ámbito de aplicación de «la existencia, validez o reconocimiento de un matrimonio» [art. 1.2.b)], se acompaña de la siguiente explicación

«Las cuestiones prejudiciales como la capacidad jurídica y la validez del matrimonio, y cuestiones como los efectos del divorcio o la separación judicial en el patrimonio, el apellido, la responsabilidad parental, las obligaciones alimentarias u otras posibles medidas accesorias deben ser determinadas por las normas sobre conflicto de leyes aplicables en el Estado miembro participante de que se trate» ${ }^{84}$.

55. Fuera también del ámbito sucesorio, un último ejemplo puede añadir datos a la pregunta que nos hacemos. Reproduciendo sustancialmente la regla del Reglamento Roma III, el Reglamento (UE) 2016/1103, del Consejo, de 24 de junio, por el que se establece una cooperación reforzada en el ámbito de la competencia, la ley aplicable, el reconocimiento y la ejecución de resoluciones en materia de regímenes económicos matrimoniales ${ }^{85}$, excluye del ámbito de aplicación material del Reglamento «la existencia, validez y reconocimiento del matrimonio» [art. 1.2.b)]. Exclusión a la que se une una explicación que opta claramente por una solución autónoma o independiente de la cuestión previa:

«El presente Reglamento no debe aplicarse a otras cuestiones preliminares, tales como la existencia, la validez o el reconocimiento del matrimonio, que siguen estando reguladas por el Derecho nacional de los Estados miembros, incluidas sus normas de Derecho internacional privado» ${ }^{86}$.

81 Bonomi, A., Informe explicativo al Protocolo de La Haya de 23 de noviembre de 2007 sobre la ley aplicable a las obligaciones alimenticias, núm. 24, en www.hcch.net.

82 Supra núm. 15, nota 32 y núm. 26.

83 HeInZE, Ch., «Bausteine eines Allgemeinen Teils des europäischen Internationalen Privatrechts», Die richtige Ordnung, Festschrift J. Kropholler, Hamburgo, Mohr Siebeck, 2008, pp. 105-127, esp. p. 115.

${ }^{84}$ Cdo. 10, KRAMER, X. et al., A European Framework for private international law: current gaps and future perspectives, Directorate General for Internal Policies, Policy Department C: Citizens' Rights and Constitutional Affairs. Legal Affairs, 2012, p. 33; Conneloup, S., op. cit., p. 197.

85 DO L 183, de 8 de julio de 2016.

86 Cdo. 21. 
56. Obviamente, debo matizar que en ninguno de los dos últimos ejemplos hablamos en puridad de una "cuestión previa» en sentido estricto, tal cual la que aquí abordamos. En lo que atañe a la validez o el reconocimiento del matrimonio, estaríamos más bien ante una Erstfrage, cuyo tratamiento natural es el proporcionado por la lex fori ${ }^{87}$ (aunque me cuesta creer que tal distinción haya estado en la mente del legislador europeo). Por otro lado, también hay que establecer el matiz de que es este un supuesto en el que el método del reconocimiento es especialmente idóneo para sustituir a las cuestiones de ley aplicable y que cuando el matrimonio se haya celebrado en el foro tampoco se plantean dudas. Por lo que se refiere a los efectos del divorcio o la separación nos encontraríamos ante una Nachfrage, que tampoco plantea las dudas que nos ocupan ${ }^{88}$.

\subsection{Las señales contrapuestas procedentes de la Comisión y del Parlamento en materia sucesoria}

57. En la Propuesta de Reglamento, la Comisión, quizá no de forma totalmente consciente, señalaba que:

«La validez y los efectos de las liberalidades son regulados por el Reglamento (CE) n ${ }^{\circ}$ 593/2008 del Parlamento Europeo y el Consejo, de 17 de junio de 2008, sobre la ley aplicable a las obligaciones contractuales (Roma I). Por consiguiente, esos aspectos deben quedar fuera del ámbito de aplicación del presente Reglamento, al igual que ocurre con otros derechos y bienes creados o transmitidos por otros medios distintos de la sucesión. Con todo, es la ley sucesoria, determinada en virtud del presente Reglamento, la que ha de precisar si una liberalidad o cualquier otro acto inter vivos que tenga por efecto la adquisición inmediata de un derecho real debe estar sujeta a una obligación de imputación, reducción o toma en consideración en el cálculo de las partes de la herencia según la ley sucesoria» ${ }^{89}$.

58. A su vez, en el Documento de Trabajo de los Servicios de la Comisión que acompañó a la Propuesta de Reglamento se lee:

"Subject to the case law of the European Court of Human Rights, the determination of who is a "child" of the deceased (e. g. whether a child born out of wedlock is a "child" of the deceased parent or whether the child of a same-sex couple is the child of both parents) would therefore still be governed by the national conflict of law rules on family law of the jurisdiction seized $"{ }^{90}$.

59. Si aplicamos sin más la plantilla de las posibles soluciones a la cuestión previa, nos encontramos aquí ante una proposición de solución independiente, en el primer caso en favor de una normativa ya unificada (Reglamento Roma I); en el segundo, en favor una no unificada.

\footnotetext{
87 BernitT, C. Ch., op. cit., pp. 12-17.

${ }^{88}$ Ibid., pp. 20-21.

89 Bruselas, 14 de octubre de 2009, COM(2009) 154 final 2009/0157 (COD), cdo. 9.

90 Bruselas, 14 de octubre de 2009, SEC(2009) 410 final (el documento completo solo en inglés).
} 
60. Es verdad que a primera vista el cdo. 9 de la Propuesta no parece estar destinado a dar una respuesta a la Pregunta núm. 13, sino más bien a delimitar el «ámbito de aplicación material» del entonces futuro Reglamento. Y probablemente así fuese. No obstante, ya vimos que la idea de tratar el tema que nos ocupa como una cuestión de ámbito de aplicación estaba presente en las respuestas al Libro Verde ${ }^{91}$, amén de ser absolutamente ortodoxa: una de las formas teóricas de abordar el problema de la cuestión previa es describirlo como una cuestión de "delimitación» ${ }^{92}$ (el problema se reduciría a elegir entre dos normas de conflicto cuyos supuestos de hecho incluirían potencialmente la situación cuestionada), o de «calificación» más o menos amplia ${ }^{93}$. Volveré sobre esta dimensión más adelante ${ }^{94}$.

61. Dicho esto, y volviendo de nuevo a la comprensión más aparente de la Propuesta de la Comisión, es decir, pensar que está respondiendo a la cuestión previa de validez de una donación respecto de una sucesión, sus consecuencias serían las mismas que con carácter general hemos visto más atrás ${ }^{95}$ : la consagración de una coherencia interna, pero esta vez no en un nivel estatal, sino europeo: aplicación de la norma de conflicto de la lex fori europea.

62. Junto a esta propuesta que, vuelvo a repetir, no creo que fuese totalmente consciente de estar dando una respuesta global al problema de la cuestión previa, el Parlamento, este sí de forma directa, aunque quizá tampoco suficientemente consciente de los efectos, se manifestó en sentido contrario. La Resolución del Parlamento Europeo que contiene recomendaciones a la Comisión sobre sucesiones y testamentos señalaba:

«que el acto legislativo que se adopte deberá someter la reglamentación de la cuestión preliminar a la ley designada por las normas de conflicto competentes de la ley aplicable a la sucesión, precisando que la solución solo será válida respecto al procedimiento en el cual se ha planteado la cuestión preliminar» ${ }^{96}$.

63. Si la llevamos al ejemplo del cdo. 9 de la Propuesta de Reglamento, esto vendría a significar:

«que el acto legislativo que se adopte deberá someter la reglamentación de la cuestión preliminar [validez de una donación a los efectos de su eventual cómputo, imputación, reducción o colación] a la ley designada por las normas de conflicto competentes de la ley aplicable a la sucesión [la que sea: última residencia habitual del causante, más estrechamente vinculada o la elegida, pero NO al Reglamento Roma I], precisando que la solución solo será válida respecto al procedimiento en el cual se ha planteado la cuestión preliminar».

91 Supra núms. 44 y 45.

92 Sobre el concepto Álvarez GonzÁlez, S., "Comentario al art. 12.1 del Código civil», en AlbalaDeJo, M. y Díaz Alabart, S. (dirs.), Comentarios al Código civil y compilaciones forales, t. I, vol. 2, 2. ${ }^{\text {a ed., }}$ Madrid, 1995, pp. 842-880, esp. pp. 853-855.

93 Solomon, D., op. cit., p. 361. GössL, S. L., «Preliminary Questions in EU Private International Law», Journal of Private International Law, 2012, núm. 8, pp. 63-76, esp. pp. 66-67, habla de «amplia calificación» para rechazarla en el ámbito europeo por problemas de competencia legislativa.

94 Infra núms. 69 y ss.

95 Supra núms. 17 y ss.

96 2005/2148(INI): DO C 314 E/344, de 21 de diciembre de 2006. 
Posición dependiente o ex lege causae que pretendía ser de alcance limitado (al procedimiento concreto) y que no llegó a plasmarse en regla.

\subsection{Las señales contrapuestas procedentes de la doctrina}

64. Lo sorprendente sería lo contrario. Sumando opciones a las ya descritas respuestas al Libro Verde, lo primero que hay que indicar es que aquella heterogeneidad se ve también reflejada en las opiniones doctrinales que se han manifestado sobre el tema. Se trata de una heterogeneidad que en parte ya he ido adelantando implícitamente y que tiene reflejo en dos incógnitas básicas: en primer lugar, la conveniencia o inconveniencia de que exista una solución expresa a la pregunta considerada; en segundo término, en su caso, el sesgo de la solución a la cuestión previa.

65. Sobre la primera, hay quienes han reclamado una respuesta concreta en un nivel europeo y quienes la consideran inoportuna o innecesaria. Entre los primeros podemos también diferenciar los que abordan el tema en términos generales, sin atender específicamente al tema sucesorio, por más que sea en este ámbito en el que parece que confluyen los problemas más recurrentes, de quienes la reclaman, precisamente para o bien al hilo de las sucesiones internacionales ${ }^{97}$.

66. Plantearse una regulación específica de la cuestión previa en el ámbito europeo comienza a vincularse a una idea global de codificación o de reestructuración del ya relativamente amplio número de instrumentos sobre conflictos de leyes ${ }^{98}$. La Agenda de Justicia de la UE para el año 2020 - Reforzar la confianza, movilidad y crecimiento dentro de la Unión ${ }^{99}$ invita a una eventual «codificación» de dichos instrumentos, que se considera especialmente útil en este ámbito. La conveniencia de un Reglamento Roma-0 en el que la cuestión previa encontraría una solución general es hoy en día un tópico de actualidad $^{100}$ que, no obstante, sigue siendo muy discutida: junto a quienes se oponen radicalmente a su regulación por considerarla un «tóxico» en la Europa de los 27 (hoy, por el momento, 28) ${ }^{101}$, están quienes igualmente ven

97 LEIN, E., «The Commission Proposal for a Regulation on Succession», YPIL, 2009, núm. 11, pp. 107-141, esp. pp. 138-140 (interpreto que implícitamente); implícitamente también DöRNER, H., «Der Entwurf einer europäischen Verordnung zum internationalen Erb —und ErbverfahrensrechtÜberblick und ausgewählte Probleme», Zeitschrift für Erbrecht und Vermögensnachfolge, 5/2010, pp. 221-228, esp. p. 223

98 LeIBle, S. y MüLler, M., «A General Part for European Private International Law? The Idea of a "Rome 0 Regulation”», YIPL, 14 (2012/2013), pp. 137-152, esp. pp. 144 y ss., 152; WELLER, M., "Mutual Trust: In Search of the Future of European Private International Law», Journal of Private International Law, 2015 (1), pp. 64-102, esp. p. 80.

99 Strasbourg, 11 de marzo de 2014, COM(2014) 144 final.

100 Von HeIN, J. y RÜHL, G., "Towards a European Code on Private International Law?», Crossborder activities in the EU Making life easier for citizens, Policy Department C: Citizens' Rights and Constitutional Affairs, 2015, pp. 8-53, y la doctrina allí citada. Recientemente, General Principles of European Private International Law, op. cit., passim.

101 Mäsch, G., op. cit., pp. 218-219. 
graves dificultades para una hallar una solución general (y eficaz), más allá de las soluciones particulares que puedan encontrarse en cada reglamento ${ }^{102}$, quienes, favorables a una codificación de una parte general del DIPr europeo, simplemente, obvian la cuestión previa ${ }^{103}$, o quienes consideran que se trata, por el contrario, de una cuestión que debe ser tenida en cuenta en una posible parte general del DIP europeo ${ }^{104}$.

67. Sobre la segunda, la que daría cumplida respuesta a la Pregunta núm. 13, las posiciones son igualmente dispares, si bien no suelen apartarse de la dualidad básica más recognoscible: solución independiente ${ }^{105} \mathrm{o}$ solución dependiente ${ }^{106}$, incluso para relativizar la opción ${ }^{107}$, para optar por una u otra, según los casos ${ }^{108}$, o para optar y matizar una y otra vez. No me resisto a poner de manifiesto lo llamativo que resulta en este trasiego de opiniones el descuido que en ocasiones reina a la hora de "clasificar» a cada autor como defensor de una solución u otra. En la mayoría de los casos las posturas son más plurales que lo que las citas cruzadas de los diversos autores indican.

68. En todas estas tomas de posición, y en las que hemos ido viendo a lo largo del trabajo, hay algunos tópicos que se repiten de forma recurrente como catalizadores de las respuestas a la pregunta que nos hacemos y que, para ir recapitulando, merecen análisis: uno de los más visibles es el que pivota en torno al «ámbito de aplicación» del Reglamento (o de los reglamentos); otro la traducción al espacio europeo de la dialéctica "armonía internaarmonía internacional». Dentro de este segundo, abordaré el argumento que vincula la cuestión previa al reenvío desde su denominador común, armonía internacional, y otro de los parámetros potencialmente definidores de la res-

102 VON HeIN, J. y RÜHL, G., op. cit., p. 37.

103 Bariatti, S. y Pataut, E., "Codification et théorie générale du droit international privé», en Fallon, M., Lagarde, P. y Poillot-Peruzzetto, S. (dirs.), Quelle architecture pour un code européen de droit international privé?, Bruselas, Peter Lang, 2011, pp. 337-361. En esta misma obra, la propuesta de LAGARDE, P. (pp. 365-376) tampoco la contempla.

104 Lechner, K., «EU Regulation 650/2012 on successions and on the creation of a European Certificate of Succession", Cross-border activities..., op. cit., pp. 113-149, esp. p. 123.

105 Max Planck Comments, núm. 8 (con matices); BernitT, C. Ch., op. cit., p. 234; LooscheLDERS, D., «Die allgemeinen Lehren des Internationalen Privatrechts im Rahmen der Europäischen Erbrechtsverordnung», Zwischenbilanz. Festschrift für Dagmar Coester-Waltjen, Gieseking, Bielefeld, 2015, pp. 531-542.

106 Con carácter general para la cuestión previa en sentido estricto, KREUZER, K. F., op. cit., p. 56. Dörner, H., op. cit., p. 224 (al menos para el CSE); Henrich, D., op. cit., pp. 64-65 (para CSE); DutTA, A., "Das neue internationale Erbrecht der Europäischen Unión- Eine esrte Lektüre der Erbrechtsverordnung», FamR, 2013, pp. 4-15, esp. pp. 13 y 15 (para la cuestión de régimen económico y CSE); $i d$., "Gemeinsame oder getrennte Kodification von IPR und IZVR auf europäischer Ebene», en von HeIn, J. y RÜHL, G. (eds.), Kohärenz, im Internationalen Privat-und Verfahrensrecht der Europäischen Union, Tubinga, Mohr Siebeck, 2016, pp. 27-43, esp. p. 42 (para el CSE, de forma implícita o hipotética); KLEINSCHMIDT, J., op. cit., p. 766, también para el CSE, sin prejuzgar la solución para el resto de supuestos; LECHNER, K., op. cit., p. 123, con carácter general. En igual sentido, la primera comisión del Deutscher Rat, en sesión de 11 y 12 de octubre de 2010 (dato que extraigo de MARTINY, D., «Die Kommissionvorschläge für das international Ehegüterrecht sowie für das internationale Güterrecht eingetragener Partnerschaften», IPRax, 2011, pp. 437-458, esp. p. 442, nota 86).

107 CORneloup, S., op. cit., 215.

108 Henrich, D., op. cit.; HeInZE, Ch., op. cit., pp. 113-114. 
puesta a la cuestión previa en la UE, que distingue entre materia unificada vs. materia no unificada (en relación al objeto propio de la cuestión previa).

\section{RECAPITULACIÓN}

\subsection{La delimitación del ámbito de aplicación del Reglamento como factor de solución implícita}

69. Una de las razones frecuentemente esgrimidas a favor de la solución independiente es que las cuestiones previas que nos ocupan están fuera del ámbito de aplicación del Reglamento. El aludido cdo. 9 de la Propuesta de Reglamento iba en esa dirección. Parte de la doctrina también incide en ella, considerando que admitir la solución dependiente sería reintroducir esas materias excluidas por la puerta de atrás de una presunta remisión integral a la ley reclamada ${ }^{109}$. Como vimos, dicha idea también está presente en las respuestas al Libro Verde ${ }^{110}$.

70. A mi juicio hay dos formas, empero, de ver esta aproximación a la cuestión previa basada en la dualidad materia incluida-materia excluida. La primera significaría que eludir directamente el problema (eventualmente conflictual) de la cuestión previa y/o tratarlo como una cuestión de ámbito de aplicación del Reglamento (o de cualquier otro reglamento) supone considerar que con las exclusiones (por ejemplo, las citadas de su art. 1) se estaría, al menos implícitamente, dando respuesta a la pregunta que nos formulamos: solución autónoma o independiente con consiguiente aplicación de la norma de conflicto del foro, sea esta de origen autónomo (por ejemplo, estado civil, hasta la fecha) o no (por ejemplo, validez de una donación).

71. Pero moviéndonos en un nivel de razonamiento general tal consecuencia no es la única posible. La segunda forma de ver el argumento nos diría que la exclusión de una materia del ámbito de aplicación del Reglamento tiene prima facie como efecto que las reglas del Reglamento no se aplican a los temas excluidos cuando se plantean como cuestión principal. Si no se regula una materia, corresponde su regulación a otro instrumento o a la ley del foro, pero incluyendo también la visión de este foro sobre la resolución a las «cuestiones previas». Ciertamente, el foro puede ser el de cada EM... o un foro europeo. En el primer caso, decide la visión eventualmente diversa de cada EM. En el segundo, hablamos de una única «solución europea», que es precisamente lo que nos estamos cuestionando ${ }^{111}$.

109 Looschelders, D., op. cit., p. 538.

110 Supra núms. 44 y 45.

111 CoRneloup, S., op. cit., p. 208, haciendo hipótesis de la cuestión, como con posterioridad le recuerda LAGARdE, P. (p. 223); también hace esa derivación Fulchiron, H., «La reconnaissance au service de la livre circulation de personnes et de leur statut familial dans l'espace européen", Mélanges en l'honneur du Professeur Bernard Audit, París, LGDJ, 2014, pp. 359-381, esp. p. 369, aunque, a mi juicio, a pesar de hablar de una cuestión previa, se está refiriendo más bien a una Erstfrage. 
72. Mutatis mutandi aceptar que la solución a la cuestión previa se liquida en términos de ámbito de aplicación de la norma es como decir que dado que el art. 9.8 CC no regula el matrimonio o la filiación (algo obvio) ello supone una toma de partido por una solución independiente a la cuestión previa. Y no es necesariamente así: precisamente la cuestión previa es conflictiva porque hay más de una norma conflicto que entra en juego (aceptando como hipótesis que tanto la solución independiente como la dependiente son posibles). Por otro lado, este razonamiento formal solo excluiría directamente la aplicación a la cuestión previa del Derecho material de la ley rectora de la cuestión principal, pero no, por ejemplo, sus normas de conflicto (solución dependiente). La consecuencia en términos de delimitación del ámbito de aplicación de la norma sería más parecida a esta: el art. 9.8 CC (en su caso, Reglamento) no regula la filiación [...], por lo que la ley sustantiva a la que remite solo se aplica a los aspectos sucesorios cubiertos por su supuesto de hecho; la ley aplicable a la filiación habrá de regularse potencialmente por otra ley: cómo se identifica esa ley es algo que no deriva directamente de lo que sí regula el art. 9.8 CC (en su caso, Reglamento). Volviendo al Reglamento (y vale para cualquier otro), lo único que cabría señalar es que, sencillamente, no dice nada sobre la cuestión previa ${ }^{112}$.

73. Resultaría, por otro lado, un tanto contradictorio señalar, como generalmente se hace, que el Reglamento no posee una solución a la cuestión previa, y al mismo tiempo ofrecerla a través de la delimitación de su ámbito de aplicación. Sin embargo, hay que reconocer que esta crítica que realizo, y que considero válida en términos intraordinamentales, tiene un recorrido distinto en el Derecho de la UE, del que también se han hecho eco algunos autores: el de la legitimidad de la propia UE para toma postura sobre temas ajenos a su competencia. La idea es que el legislador europeo no tendría competencia para regular la filiación de una persona, o el matrimonio, por ejemplo. Existiría así una diferencia importante: el tratamiento de la cuestión previa dentro de un mismo sistema - como regla y dejando ahora de lado la asunción de algunas de esas competencias por la UE - presume que el legislador estatal tendría competencia para determinar la ley aplicable tanto a la cuestión principal (por ejemplo, sucesiones) cuanto a la cuestión previa (por ejemplo, filiación); sin embargo, el legislador de la UE puede no tener, o no haberla asumido, o ser discutible que tenga dicha plenitud de competencia legislativa ${ }^{113}$. Mas, señalada la especialidad, la consecuencia sería la misma: no la asunción de una solución independiente a la cuestión previa, sino la constatación de una «no solución».

74. Quede constancia, en todo caso, de que el argumento no vale cuando la UE sí tiene competencia para regular tanto la materia objeto de la cuestión principal, cuanto la materia objeto de la cuestión previa. En estos casos, del reproducido cdo. 9 de la Propuesta, se podría extraer la regla según la cual la

112 Solomon, D., op. cit., p. 370, aunque el razonamiento contrario también es posible (pp. 369370); DutTA, A., «Das neue internationale Erbrecht... », op. cit., p. 13.

113 GössL, S. L., «Preliminary Questions...», op. cit., p. 67. 
cuestión previa en los supuestos en que esté regulada por una norma europea se resuelve de manera independiente.

\subsection{Armonía interna versus armonía internacional en la UE}

75. Otra de las líneas de discusión habitual en la búsqueda de una solución "europea» a la cuestión previa es la de proyectar los clásicos tópicos de armonía internacional versus armonía interna a la realidad del Derecho europeo. ¿La peculiaridad de la UE condiciona o determina la respuesta a la cuestión previa en términos de armonía interna o internacional?

76. La respuesta a esta pregunta debe partir de dos premisas. La primera es el valor mismo de la idea de armonía, sobre todo, la de armonía internacional de la que se nutre la solución dependiente. En este sentido, nos encontramos con dos realidades en cierto modo contrapuestas. Por un lado, el hecho de que el núcleo duro del DIPr de la UE rechace de forma generalizada la toma en consideración de normas de conflicto de la lex causae ${ }^{114}$ es utilizado por quienes combaten la idea de la solución dependiente ${ }^{115}$. La armonía internacional no es tan relevante, sería la premisa y la conclusión. Por otro lado, tenemos la realidad del Reglamento de sucesiones, que rompiendo esa dirección concede un cierto espacio al reenvío (art. 34), justificado, precisamente, en aras a la armonía internacional de soluciones ${ }^{116} \mathrm{o}$ la "coherencia internacional» en los términos del propio Reglamento ${ }^{117}$. ¿Que deriva de ambas realidades? A mi juicio, ninguna de las dos es decisiva. La exclusión del reenvío o su admisión ni determina ni condiciona en nada una concreta solución a la cuestión previa. Digamos, a mayor abundamiento, que la armonía internacional no es más que un factor (ni siquiera necesariamente presente) en el mecanismo del reenvío, más complejo y más nutrido de otros muchos ${ }^{118}$. Y desde la perspectiva de su capacidad para determinar una solución concreta a la cuestión previa, la armonía (la que sea) debe ceder a favor de la preponderancia de intereses privados, de los participantes y la concreta situación ${ }^{119}$.

77. La segunda premisa es la refutación de principio más atrás presentada en torno a la idea de armonía internacional ${ }^{120}$. Planteada una cuestión previa de filiación, el hecho de que la ley aplicable a la sucesión derive del art. 9.8

114 Arts. 20 del Reglamento Roma II, 24 del Reglamento Roma II, y 11 del Reglamento Roma III. A los que podemos añadir el art. 12 del Protocolo de alimentos de La Haya, el art. 32 del Reglamento de regímenes económicos matrimoniales (supra nota 85) o el art. 32 del Reglamento (UE) 2016/1104, del Consejo, de 24 de junio, por el que se establece una cooperación reforzada en el ámbito de la competencia, la ley aplicable, el reconocimiento y la ejecución de resoluciones en materia de efectos patrimoniales de las uniones registradas (DO L 183, de 8 de julio de 2016).

115 GössL, S. L., «Die Vorfrage...», op. cit., p. 71; Mäsch, G., op. cit., p. 207.

116 Bonomi, A., en Bonomi, A. y Wautelet, P., op. cit., pp. 436 y ss.

117 Cdo. 57

118 Romano, G. P., Le dilemme du renvoi en droit international privé. La thèse, l'antithèse et la recherche d'une synthèse, Ginebra-Zurich-Basilea, Schulthess, 2014, passim.

119 MÄsch, G., op. cit., p. 211.

120 Supra núms. 18 a 20. 
CC (causante con última nacionalidad peruana) o del art. 21 del reglamento (causante con última residencia habitual peruana) no cambia nada lo dicho: la armonía internacional es absolutamente aleatoria, optemos por una solución dependiente o independiente. No puede ser parámetro de decisión alguno. En nuestro caso (Reglamento de sucesiones) no es la armonía internacional lo que está en juego sino la armonía o coherencia respecto del resto de los EM. Y esta podría considerarse como una especie de armonía o coherencia interna (de una lex fori europea) que, recordemos, sí tiene consistencia per se $e^{121}$, y cuya consecución exige distinguir, al menos, dos situaciones, según la ley aplicable a la cuestión previa esté también unificada o, por el contrario, no lo esté.

78. En el primer caso, da igual qué solución se siga para la cuestión previa, a pesar de una cierta opinión en considerar que en estos casos la solución independiente sería la obligada ${ }^{122}$. Si se opta por la independiente, en todos los EM se aplicaría la misma solución por mor de la unificación: sería el caso de la cuestión previa de validez de una donación a efectos de la sucesión (todos los EM aplican Roma I). Si se opta por la dependiente, todos aplicarían también la misma solución, esta vez derivada de la norma de conflicto de la ley rectora de la cuestión principal (que es la misma para todos), aunque, en este caso, con más elementos de aleatoriedad: la aplicación de una norma de conflicto unificada, potencialmente interpretada de forma uniforme por el TJUE, conocida y familiar a todos los EM, no es lo mismo que la aplicación de la norma de conflicto de un tercer Estado.

79. Si, por el contrario, solo está unificada la ley aplicable a la cuestión principal y no la aplicable a la cuestión previa (por ejemplo, sucesión y filiación natural), la armonía o coherencia entre los EM precisaría de una solución dependiente (ex lege causae). Ciertamente, se trataría, en este caso, de una armonía o coherencia respecto de los EM parcial: solo limitada a la cuestión principal sucesoria, pero no a la cuestión previa, en nuestro ejemplo de filiación, que seguiría al albur de cada solución estatal de presentarse como cuestión principal ${ }^{123}$. Se trata de una solución esta que incluso plantea reservas a quienes la proponen; reservas derivadas de la afectación de la coherencia interna en cada EM o del omnipresente límite derivado del ámbito de aplicación de cada instrumento ${ }^{124}$. Más aún, la misma cuestión previa de filiación podría tener una solución «europea» distinta en función del instrumento europeo aplicable y, consiguientemente, de la ley aplicable a la cuestión principal: piénsese, por ejemplo, para la misma filiación, en que la solución dependiente sería diversa ante la aplicación de la ley nacional como ley sucesoria y ante la de la residencia habitual como ley rectora de los alimentos ${ }^{125}$. Y todo ello, sujeto incluso a las vicisitudes que puede aparejar el

121 Supra núm. 22.

122 BERnITT, C. Ch., op. cit., pp. 135-136, más en términos de «legitimidad» que de «armonía»; GössL, S. L., «Preliminary Questions...», op. cit., pp. 67-68; HeINZE, Ch., op. cit., p. 113.

123 Solomon, D., op. cit., pp. 367-368.

124 HeInZE, Ch., op. cit., p. 114.

125 Max Planck Comments, núm. 7. 
proceso de identificación y aplicación de la ley aplicable a la cuestión previa, en caso de estar esta gobernada por un Derecho extranjero: diferentes concepciones en cada EM sobre su aplicación, diferentes concepciones en cada EM en cuanto a la vulneración de su orden público ${ }^{126}$.

\section{CONCLUSIÓN}

80. Advertí en la introducción de que la obtención de certezas o de una respuesta segura a la Pregunta núm. 13 del Libro Verde no iba a ser posible. Creo que los desarrollos que nos han llevado hasta aquí lo atestiguan. El primer acercamiento a la propia realidad, plural, muy plural, que históricamente se ha tratado de comprimir bajo el concepto de «cuestión previa» no era un buen augurio. Si algo ha quedado claro, al menos para mí, es que cualquiera que hubiese sido la respuesta en términos positivos se habría hecho acreedora de las críticas que, según las distintas posturas referenciadas, se hacen a la solución independiente, a la dependiente, a cualquier otra o a todas ellas.

81. En algún momento me referí a la opinión de los Profs. H. Dörner y P. Lagarde, según la cual la regulación de la cuestión previa no resultaba muy conveniente a la luz de la escasa práctica comparada y de las grandes discrepancias doctrinales que la envolvían. Creo que tenían razón. Lo cual no deja de ser frustrante. No por no poder demostrar lo contrario, ni por no ser previsible que, al menos, a partir de ahora se diga que «Dörner, Lagarde y Álvarez opinan que...», sino porque, como dije al principio, el hecho de no encontrar una solución satisfactoria a la cuestión previa no significa que los variados problemas que sintetizamos bajo su figura dejen de existir.

82. Y tampoco puede resultar consuelo coincidir con que cuanto mayor sea la aproximación y permeabilidad en Derecho comparado, cuanto más unificación conflictual, cuanto más avance la idea del reconocimiento alimentada por reglas, por el TJUE o por los derechos humanos interpretados por el TEDH, menos "cuestión previa» habrá ${ }^{127}$. De momento las hay y no parece previsible que desaparezcan.

83. Ante este panorama, creo que lo más sensato es cambiar el concepto. Cambiar la forma de ver los problemas, eliminando el corsé de la teoría de la "cuestión previa». Eliminarla sin más y con ella sus propuestas de solución. Reducirla, por ejemplo, a una cuestión de interpretación de la ley (de la lex materialis causae) sin ataduras ni compromisos conflictuales. El método del reconocimiento, con sus carencias, se orienta en esa dirección. También en un plano doctrinal, muchas de las excepciones que unos y otros plantean a sus propias propuestas principales indican el camino del tratamiento singular, de la solución ad hoc, con o sin la intermediación necesaria de una «norma de conflicto».

\footnotetext{
126 Supra núm. 19.

127 Henrich, D., op. cit., p. 72.
} 


\section{RESUMEN}

\section{¿QUÉ NORMA DE CONFLICTO DE LEYES HAY QUE ADOPTAR PARA DETERMINAR LA LEY APLICABLE A LAS CUESTIONES PREVIAS A EFECTOS DE LA SUCESIÓN?}

En este trabajo se aborda el tema clásico de la «cuestión previa» en DIPr. El punto de partida es la Pregunta núm. 13 del Libro Verde Sucesiones y testamentos.

Falta acuerdo en torno a la respuesta a la cuestión previa. Esta es la justificación de cualquier problema teórico. Sin embargo, tampoco hay consenso en torno al concepto de la cuestión previa. Y esto es algo que dificulta cualquier discusión rigurosa.

En este escenario, se propone rechazar la teoría (rectius, teorías) de la cuestión previa y adoptar un enfoque casuístico. Este enfoque ad hoc se fundamentaría, entre otras razones, en las múltiples reglas y excepciones (muchas de ellas muy razonables) propuestas por los autores, en especial la doctrina alemana.

En algunos casos el «reconocimiento» (y no la ley aplicable) puede ser el enfoque más adecuado; en otros, cualquiera de las propuestas clásicas [...] proporcionará la mejor respuesta, dependiendo de las circunstancias y del interés preponderante en el supuesto; también es posible evitar el problema a través de una "calificación» funcional de la situación.

La debilidad de esta propuesta, la falta de seguridad jurídica, es manejable y, en cualquier caso, la propuesta no es más débil que el escenario actual sumamente heterogéneo.

Palabras clave: sucesiones, Derecho internacional privado, cuestión previa, UE.

\section{ABSTRACT \\ WHAT CONFLICT RULE SHOULD BE ADOPTED TO DETERMINE THE LAW APPLICABLE TO PRELIMINARY QUESTIONS ON WHICH THE SUCCESSION MAY DEPEND?}

This paper deals with the classic topic of «incidental or preliminary question» in the conflicts of laws. The start point is the question $\mathrm{n}^{\circ} 13$ of the Green Paper Succession and wills.

There is no consensus on the answer to the incidental question. Understandable, as this is indeed the begin of every theoretical problem. However, there is no consensus either regarding the concept of incidental question. And this is something that precludes any proper discussion.

As a result, the author proposes to reject the theory (rectius: the theories) of the preliminary question and to adopt a case by case approach. This ad hoc approach is based, among other reasons, upon the multiple rules and exceptions (many of them very reasonable) proposed by authors, especially in German doctrine.

In some cases "recognition" (and not conflicts of laws) can be the most appropriate approach; in others any of the classic proposals [...] will provide with the better answer, depending on the circumstances and the most preponderant interest involved; it is also possible to avoid the problem through a proper "characterization» of the situation.

The main weakness of this proposal, that is, the requirements of legal certainty, is a fully manageable one, and in any case it is a proposal not weaker than the current heterogeneous scenario.

Keywords: successions, conflict of laws, incidental question, EU. 